germ? He has been pleased with the reports others have made on the use of this method. He has put this remedy into the hards of over a hundred patients and it has invariably benefited them. Dr. Prince declared that he is satisfied, and that when he can use a remedy for years and get good results he considers it a good thing. The bulletins referring to the experiments are accessible. Since he claims no authorship in the experiments, he invites an examination of the abovementioned reports. This remedy does not cure all cases. It is an adjuvant to other methods. It is safe; it is cheap. Dr. Prince hopes that his judgment may be backed.by the experience of the profession.

\section{THE OCULAR TYPHOID REACTION.}

\section{PRELIMINARY REPORT OF A MODIFICATION OF THE OCULAR TEST OF CHANTEMESSE.* WALTER W. HAMBURGER, M.D. \\ CHICAgo.}

On July 23, 190\%, Professor Chantemesse ${ }^{1}$ announced at a meeting of the $\Lambda$ cademy of Medicine in Paris a new characteristic reaction for the diagnosis of typhoid fever. Two months later ${ }^{2}$ he published the results of this diagnostic test applied to 128 patients, together with a brief description of its method of application.

The test consisted of the instillation into the conjunctival sac of one drop of a solution made as follows: Gelatin plates covered with an 18 to 20 hour old culture of virulent typhoid bacilli were washed with 4 to 5 c.c. of sterile water. The suspension thus obtained was heited to $60 \mathrm{C}$., centrifugated and the supernatant fluid withdrawn. The centrifugated organisms were then dried and triturated. A second suspension of these broken up bacillary bodies was then made and allowed to stand for from two to three days at $60 \mathrm{C}$. The extract thus obtained after removing the disintegrated and digested rests was precipitated with alcohol, forming a fine coagulum. This was subsequently dried and powdered and dissolved in sterile water in the proportion of $0.02 \mathrm{mg}$. to a drop.

In a series of 128 cases, 70 cases diagnosed clinically as typhoid fever and giving positive agglutination reactions were tested. From two to three hours after instillation a diffuse redness of the conjunctiva was noted, together with a subjective sensation of warmth in the eye. Later lachrymation and slight exudation appeared in some instances. In from six to ten hours, the reaction had reached its height and persisted through the following day. This Chantemesse calls the "Ophthalmo-typhoid" reaction. All the cases responded positively.

Fifty cases of the series consisted of patients sick or convalescent from various diseases other than typhoid. These did not give a positive agglutination test. On dropping in the solution, most of the eyes suffered a slight reddening and conjunctivitis which disappeared usually in four or five hours. This is spoken of as a negative reaction. The differentiation is based on the variation in intensity and duration of the inflammatory reaction.

Eight cases, tested early in the disease from the fifth to the twenty-first day gave a positive ocular test while the serum reaction was still negative. These all gave positive agglutination tests later in the course of the dis-

* From the clinical laboratories of the Presbyterian Hospital.

1. A brief report appeared in the Deutsche med. Wochschr., 1007 . No. 31, p. 1264

․ Lophthaimo-diagnostic de Ia Fièvre typhoide, Deutsche med. li.hschr., 1907 , No. 39, p. 1572 ease. It is more particularly on the evidence offered by these eight cases that Chantemesse states the particular interest in the ocular reaction lies, in so far that a positive diagnosis of typhoid might be obtained days before the sero-diagnosis appeared. Further, many cases now allowed to go undiagnosed because of the failure of an early agglutination, would be elucidated, thus extending our knowledge of the disease and of the domain of infections caused by the typhoid bacillus.

The observations here recorded were made with the hope of confirming the results of Chantemesse by the use of a typhoid extract prepared in a much simpler way. The solution was prepared by Dr. D. J. Davis as follows: The bacteria were grown for twenty-four hours on plain agar slants. They were then washed from the surface with plain salt solution and an emulsion prepared, which contained $3,000,000,000$ bacilli per cubic centimeter. This was placed in the incubator for four days at $37.5 \mathrm{C}$. At the end of this time the bacteria were removed by prolonged centrifugation and the supernatant almost clear fluid was drawn off and heated to $60 \mathrm{C}$. for 30 minutes. This fluid was tested and found to be sterile. No bacilli were found in stained smears. The fluid thus prepared was used for the tests, the usual precautions as to cleanliness, care in instillation, etc., being as strictly obserred as in the teclinic of ocular tuberculin manipulations.

TABI.E 1.3-Twenty-Seven Cases Diagrosed Clinically as Typhoid Fever, Givisa Eitiler a Positile aggletication Test or Blood Cllture ani Reactisa Positively to the Occhar Test.

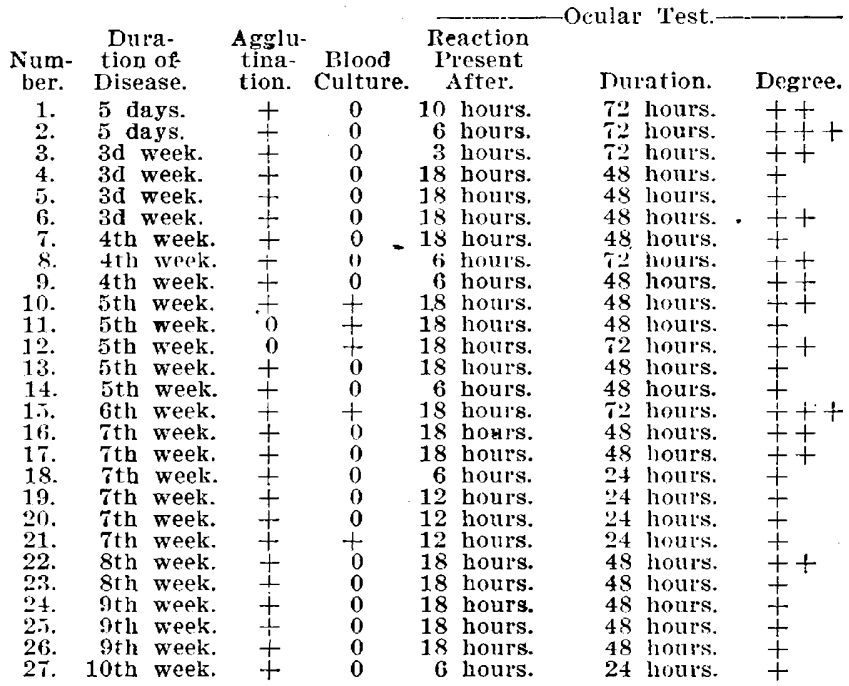

The reaction was tried in a total of forty-eight cases; twenty-seven cases diagnosed clinically as typhoid fever gave a positive agglutination test or blood culture and reacted positively to the ocular test (Table 1); fifteen control patients, suffering clinically from a varicty of maladies other than typhoid fever, failed to react; six cases diagnosed clinically as typhoid fever but not presenting either a positive agglutination reaction or a blood culture were likewise tested, resulting in four negative and two positive reactions. (Table 3.)

The positive reactions obtained in the proved up cases

3. Fxplaxation of Tables. - The hours indicate when eye was first observed after instillation: reaction donbtless began earlier. The intensity of reaction has been symbolized in the last column as follows:

$+\quad$ Diffuse palpebral injection with little, if any discharge.

++ Deep palpebral injection; beginning corneal injection; slight mucopurulent discharge.

+++ Marked palpebral and ocular conjunctivitis with pronounced mucopurulent discharge; slight edema of lids: 
presented a number of interesting features. The stage of the discase bore no striking relation to the degrce of the reaction except in some instances suggesting a possible increase in intensity during the active process of the infection. In no cases was I able to obtain an ocular reaction prior to the agglutination phenomenon. Howerer. in only two anses was this tried as early as the first week. Further observations may reveal results comparalle to the eight cases of Chantemesse.

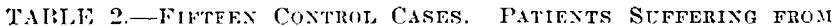

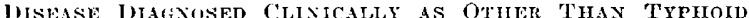

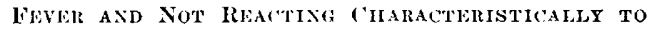
THE OCLIAR 'TEST.

\begin{tabular}{|c|c|c|c|}
\hline & & & \\
\hline & Reaction & & \\
\hline $\begin{array}{l}\text { Num- } \\
\text { ber: Clinional Iriagnosis. }\end{array}$ & $\begin{array}{l}\text { Present } \\
\text { After } \\
\text { homrs. }\end{array}$ & Duration. & Degree. \\
\hline 1. Arute artie rhatm., & 6; & Tisappeats & Slight reat- \\
\hline 2. Nenrosis. $\ldots \ldots \ldots \ldots$ & 6; & Trace remaining in & denimg. \\
\hline 3. Akolnolic neur it is... & 6 & Trace remaining in & + \\
\hline 4. I'leurisy with effusion. & (i & $\begin{array}{l}\text { Disappeared completely } \\
\text { in } 24 \text { hours. }\end{array}$ & $\begin{array}{l}\text { Slight led- } \\
\text { dening. }\end{array}$ \\
\hline ‘. Organic beart dis.. & (6 & $\begin{array}{l}\text { Disappealed completely } \\
\text { in } 24 \text { hours. }\end{array}$ & $\begin{array}{l}\text { Slight led- } \\
\text { dening. }\end{array}$ \\
\hline 6. Organie heart dis... & 6 & $\begin{array}{l}\text { Disappeared completely } \\
\text { in } 24 \text { hours. }\end{array}$ & $\begin{array}{l}\text { Slight red- } \\
\text { dening. }\end{array}$ \\
\hline †. Hour-glass stomach. & 6 & $\begin{array}{l}\text { Disappeared completely } \\
\text { in } 24 \text { hours. }\end{array}$ & $\begin{array}{l}\text { Slight l'ed- } \\
\text { dening. }\end{array}$ \\
\hline 8. Carce en rbriasse.... & ) & & \\
\hline 9. Acute art. rheum... & (; & $\begin{array}{l}\text { Disappeared completely } \\
\text { in } 24 \text { hours. }\end{array}$ & $\begin{array}{l}\text { Slight red. } \\
\text { dening. }\end{array}$ \\
\hline 10. Alc. gas & 6 & $\begin{array}{c}\text { Disappeared completely } \\
\text { in } \mathbf{2 4} \text { houl's. }\end{array}$ & 1 \\
\hline 11. Tuberculous plemisy. & . 12 & $\begin{array}{l}\text { Disappeared completely } \\
\text { in. } 24 \text { hours. }\end{array}$ & $\begin{array}{l}\text { Slight red- } \\
\text { dening. }\end{array}$ \\
\hline 12. & 0 & 0 & 0 \\
\hline 13. Chronic osteomyelitis. & 0 & 0 & 0 \\
\hline 14. Chronic Bronehitis. & 0 . & 0 & 0 \\
\hline 15. Neurosis $\quad \ldots \ldots$ & 0 & 0 & 0 \\
\hline
\end{tabular}

The earliest reaction was evident after an incubation period of three hours. Six cases examined six hours after instillation were all positive.

The average duration of the reaction was from forty-eight to secenty-two hours; the limits ranged from twenty-four to ninety-six hours.

Table 3.-Six Cases Dragnosed Chically as Trphoid Fever, bet Nut Reactivg to the AgGiditination Tes't or for Other limisons not Bersg Included in Table 1. DotbTFUl Cases.

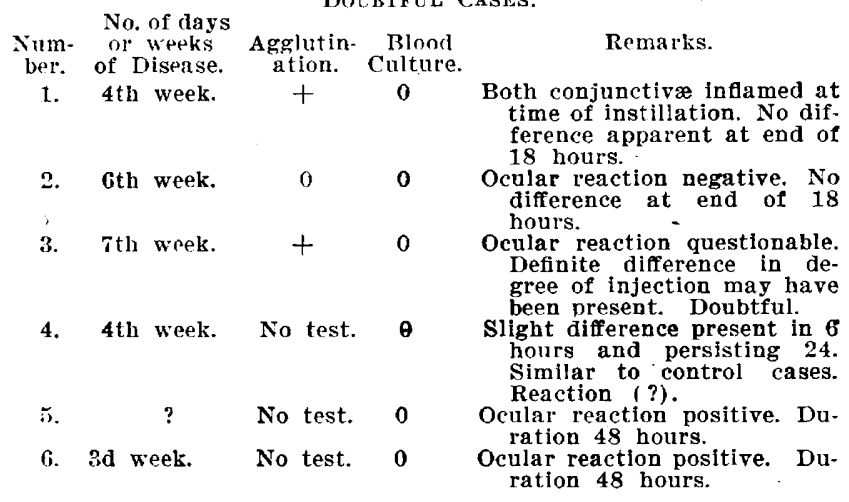

A typical reaction may be described as follows: From three to six hours after instillation there appears a dif$f$ fuse redness of the inner caruncle, plica semilunaris and palpebral conjunctiva. At the end of this period or a little later, a yellow-white, translucent mucopurulent discharge appears and collects at the inner canthus. The morning following the patient frequently complains that his eye "was stuck together when he woke up in the morning," and there are evidences of a dried crusted cxudate on the margin of the lids and on the lashes. It is the exception for patients to complain of subjective symptoms other than "watering of the eye." or smarting or soreness. The feèling of a foreign body or a grain of sand which so frequently follows an ocular tuberculin test was not complained of. Likewise the hyperemia of the caruncle was not nearly so prominent as in the tuberculin test. If there is doult as to the existence of a reaction, I have found that the conjunctiva covering the lower and outer fornix of the tested eye is the point at which the greatest injection occurs and that a comparison with the other eye may decide a doubtful case.

The negative reactions in control cases were examined critically because of the slight reddening obtained in some instances. In a total of fifteen cases five slowed no apparent change; seven showed a slight, though definite diffuse redness which disappeared entirely in twenty-four hours; three showed a more pronouncel hyperemia, which lasted over twenty-four hours, but which at no time partook of the degree of injection noted in positive cases. The presence of a slight inflammatory reaction in these negative cases has led me to the belief that there exists some irritating principle in the extract as we have prepared it and in the alcoholic precipitate of Chantemesse, which is not specific and which may be eliminated by greater dilution of the active principle or by its removal by phrsical or chemical means. Work toward this end is now under way.

The six cases classed as doubtful in Table 3 are self explanatory and are included for the sake of completeness. With the exception of the last case there is no suggestive contradiction. This patient, a woman 2.) years old, three days after instillation developed unmistakable evidence of tuberculous meningitis and died forty-eight hours later. Further inquiry revealed a history of typhoid one year previous. It is too early to say whether the ocular reaction was due to persisting bodies from the previous typhoid infection or whether the meningitis was responsible. Here again more extensive observations are needed to decide.

The series is instructive in showing the necessity of careful inspection and analyses of ocular phenomena. Until the exact limitations of ocular-typhoid tests have been ascertained by experience gained through observation of a large number of cases. one should not interpret them as final, but should weigh them carefully in conjunction with other available data.

\section{SUMMARY.}

By the instillation into the eyes of typhoid patients of one drop of an extract of the typhoid bacillus, a reactive inflammation has been caused which probably is specific and possibly universal. In diseases other than typhoid, a less intense and shorter reaction occasionally appears which in most cases may easily be differentiated. These results agree closely with those obtained with the alcoholic precipitate of Chantemesse.

Ocular Diagnosis of Tuberculosis in Chronic Tropical Affections.-Treille contributes an article on this subject to the Caducée, February 14, emphasizing the importance of detection of tuberculosis in its incipiency in persons affected with chronic tropical affections. He expatiates on the frequency with which tuberculosis becomes superposed on them. Its revelation by the ocular differential test would in many cases explain why the patients fail to recover health, and it would also be the signal for prompt return to a temperate clime. It has been his experience that tuberculosis almost invariably runs an exceptionally rapid and fatal course in the tropics. It is best not to attempt to fight it there but to return home, where it may be arrested in its incipiency by proper treatment. 